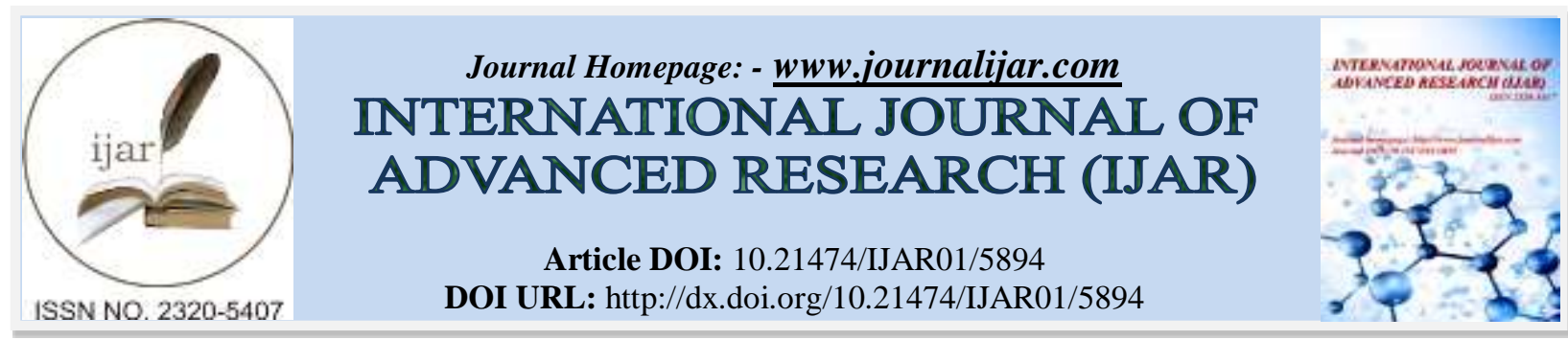

RESEARCH ARTICLE

\title{
SLEEP PATTERN AND ITS RELATED FACTORS IN RELATION TO COLLEGE STUDENT'S ACADEMIC PERFORMANCE ALMAAREFA COLLEGES, RIYADH, SAUDI ARABIA 2014/2015.
}

\author{
"Dr. Mona Hassan, Areen Al- Harbi, Asma Mohameden, Aisha NajiMohiuddin, Ghaliah Hamdan Albugami, \\ Hala Ahmed Abuhomoud, Hanan Musa, Israa Mohammed Alammari, Nada Aboalela, Rawan Adel Farhat \\ and Raya Assenay Osman and Razan Badr Alsaad. \\ Medicine Faculty member.
}

\section{Manuscript Info}

Manuscript History

Received: 17 September 2017

Final Accepted: 19 October 2017

Published: November 2017

\section{Abstract}

Introduction: Most people need to sleep around 8 hours per night or day, depending on the time they prefer to sleep. This is especially true for college students since the deep sleep that occurs early during the night, and the dream stage of sleep that occurs later during the night are both required for learning. The goal of this research was to explore and understand the sleep patterns, and its related factors and their association with the academic performance among medical college students.

Methodology: An observational, cross-sectional university-based study was conducted in early March 2015 in Almaarefah colleges. One hundred female undergraduate students of all majors of AlMaarefa were included. A self-administered questionnaire was used, and the data was analyzed using SPSS.

Results: The research showed that $51 \%$ of those who had continuous night sleep and 6-8 hours of sleep during weekdays had an improved grade point average (GPA). While $75 \%$ of those who had interrupted night sleep and more or less than 6 hours of sleep during weekdays showed lower levels in their GPA, which was statistically significant with value of $(\mathrm{p}=.0014)$. The research also showed that $74 \%$ of those who nap during the day have a rather normal sleep pattern, whereas $56 \%$ of those who don't have naps have a disturbed sleep pattern. On the other hand, stress and frequent nightmares negatively affected the sleep pattern.

Conclusion: A good academic performance in Almaarefah health students is highly associated with a good 6-8 hours of sleep. Also, good sleep was associated with naps and continuous night sleeps, which extended to affect the performance positively.

Copy Right, IJAR, 2017,. All rights reserved.

\section{Introduction:-}

What is sleep? Sleep is a state when our senses and motor activity are relatively suspended; there is total or partial unconsciousness, and all voluntary muscles are inactive. Sleep is the body's rest cycle.(1) 
Sleep is a vital physiological state or condition for humans to maintain a healthy body and lifestyle. Even though the precise functions of sleep remain a mystery, sleep is important for normal motor and cognitive function. We all recognize and feel the need to sleep. After sleeping, we recognize changes that have occurred, as we feel rested and more alert. Sleep actually appears to be required for survival.(2,3)

Sleep is thought to have a fundamental effect on human beings competence of their customary activities. Such as their social activities, personal life, work environment, academic and general performance and more.(2)

Sleeping patterns are our habitual patterns in sleep. They are affected by many factors, including age, the amount of sleep, the time of the day, or night related to an individual's internal clock. Other behaviors prior to sleep such as exercise, stress, and environmental conditions such as temperature, light and various chemicals. These factors lead to different and varied types sleeping patterns such as monophasic, biphasic, polyphasic, insomnia and other variations in the individual if there was any imbalance. (4)

Most people need to sleep around 8 hours per night or day, depending on the time they prefer to sleep. This is especially true for college students, since the deep sleep that occurs early during the night and the dream sleep that occurs later during the night are both required for learning.(5)

Academic performance refers to a student's success in meeting short- or long-term goals in education. In the big picture, academic performance means completing high school or earning a college degree. Academic performance may also refer to a person's strong performance in a given academic arena. Education associations and schools monitor the overall level of student academic performance to decide what, if any, changes need to be made in the educational system.(6)

Students of different educational levels (from school to university/college) are chronically sleep deprived or suffer from poor sleep quantity and quality which is either due to psychological, environmental or professional stress.(2)

Poor sleep quantity and quality induce several effects on the students life. Such as increased daytime sleepiness, emotional disturbances, memory loss, decreased concentration, impaired mood, behavioral changes, and neurological defects are possible.(2)

Based on that premise, we aim to outline a relationship between sleeping patterns and academic performance of college students. And in this particular piece we are rather more concerned with how sleeping patterns and their related factors affect the academic performance of college students.(2)

\section{Objectives:-}

1. To describe the sleeping patterns of college students.

2. To identify the related factors affecting the sleep patterns.

3. To verify the influence of sleeping patterns on college student's academic performance.

\section{Literature review:-}

A study was conducted in India by Kagathra in 2012. The subjects were 131 first year medical students. The aim of this study is to know sleep wake pattern in medical student, role of residence and individual characterization on sleep wake cycle. The sleep wake cycle of the students is quite different and characterized by delayed onset, partial sleep deprivation, poor sleep quality, insufficient sleep duration and occurrence of napping episodes during the day. Poor sleep quality in medical student irrespective of residence. They found poor sleep quality and sleep deprivation is more pronounced in evening type of the students and partial compensation found on weekends. Morning type students adjust their life better than evening type and manage their academic schedule.(7)

A study of Sleep Patterns and Disorders among University Students which was published in Lebanon by Assaad, this study released in 2014, the aim of this study was to investigate sleep habits and disorders in a population of university students across Lebanon,the study carried out in 2012 among 735 students aged 18-25 years old. Results of this study suggest that sleep problems such as poor sleep quality and less sleep duration among Lebanese college students were common and such problems may interfere with daily.(4) 
The study was conducted in the UAE among 105 males and 185 females by Afandi. It was conducted to evaluate the impact of external factors on sleep quality in college students. The study found that the majority of college students suffer from sleep disturbances. College students older than the age of 24 suffered from less sleep disturbances. Users of social networks got less sleep and many ended up sleeping during class. It was also found that sleep deprived students had felt a significant amount of anxiety throughout the day.(8)

The study was conducted by Loprinzi in 2011 in USA, Oregon, in the purpose of the study was to examine the association between objectively-measured physical activity and a variety of self-reported sleeping parameters, 3081 adults ranging in age between 18 and 85 were included in the analyses. This study demonstrate a link between regular PA and perceptions of sleepiness during the day, which suggests that participation in PA on a regular basis may positively influence an individual's productivity at work, or in the case of a student, influence their ability to pay attention in class. Increasingly, the scientific evidence is encouraging as regular PA may serve as a nonpharmaceutical alternative to improve sleep.(9)

Another study in Portugal in 2002 was performed out of 1150 students by Jose, 150 were chosen and it aimed to find the relationships between sleep, circadian rhythms, and academic performance and the result was that the associations between insufficient sleep duration and lower university grades are understandable in the view of sleep functions. Such findings agree with the supposition that, during sleep, learning and memory consolidation occur. based on the that, we believe that the knowledge about sleep-wake patterns and circadian rhythms may be important for a better understanding of the academic failure/success at the university.(10)

Wolfson on 2003 and it discusses the relation between sleep patterns, sleep quality, and school performance. The majority of studies related on self-report. Studies were made on two thousand thirty four college students in the united states to look at sleep/wake patterns and usual grades, school start time and phase preference in relation to sleep habits and quality and academic performance, and the results were erratic sleep/wake schedules, late bed and rise times, and poor sleep quality are negatively associated with academic performance.(11)

The objective of the present study, which is by Tyler, was examination of the relationship between sleep and college academic performance; grade point average (cumulative GPA). For the study, 1039 students were recruited from undergraduate psychology classes in Texas during 2006 and 2007. Results indicated that later bed and wake times and increased nap taking were related to lower cumulative GPAs, as were greater variability in bedtimes, wake times, total sleep time, sleep efficiency, sleep onset latency, and napping. Conversely, greater sleep efficiency was significantly related to higher cumulative GPAs.(12)

This study was conducted by Flood at Huntingon University, America 2008, on The Impact of Sleepiness Levels on Academic Achievement for College Students. The study was of a sample size of 392 students. The results did not support the hypothesis that sleepiness and GPAs would negatively correlate. The lack of statistical significance between the two variables suggests that a student's GPA is not affected by their sleepiness; therefore, other factors need to be identified that may correlate with low GPA.(13)

The study was conducted in Riyadh, Saudi Arabia in 2009 and 2010 by BaHammam. The aim of this study was to assess the relationship between sleep habits and sleep duration with academic performance. The study included 410 students, 115 students (1/3) had "excellent" performance, and 295 students (2/3) had "average" performance. The "average" group had a higher Epworth Sleepiness Scale (to evaluate daytime sleepiness) score and a higher percentage of students who felt sleepy during class. In contrast, the "excellent" group had an earlier bedtime and increased total sleeping time (TST) during weekdays. Subjective feeling of obtaining sufficient sleep was the only independent predictors of "excellent" performance. Decreased nocturnal sleep time, late bedtimes during weekdays and weekends and increased daytime sleepiness are negatively associated with academic performance in medical students.(14)

This study, which was conducted by Aabid, was designed to discover a relationship between a healthy sleeping schedule and academic success in the undergraduates in Lahore so that we may be able to encourage medical students to seek healthier sleep habits, by using academic success as motivation. The study was carried out in 2011. 591 students ( 379 female and 212 male) consented to participate. All students selected were aged between 18 to 23 years. Medical students are subjected to high levels of stress during their academic year that can lead to 
psychological problems resulting in sleep disturbances, so poorer academic performance was related significantly to reduction in night time sleep and later times of waking up in the morning.(15)

\section{Methodology:-}

Study Design:

An observational, descriptive, cross-sectional, university-based study.

\section{Study Area:}

The study was conducted at Almaarefa colleges, Riyadh, Saudi Arabia.

\section{Study Population:}

The study included female, undergraduate, college students of all majors and colleges of Almaarefa Colleges, which were (Medicine, Pharmacy D, Nursing, Computer Sciences and Respiratory Therapy) between the ages 18-25 years; of size population 1130 students. Preparatory year female students were not included.

\section{Sample Size and technique:}

This study covered 100 female students, who were selected randomly.

\section{Data Collection tool and needs:}

A self-administered questionnaire was constructed, and it contained four sections. First section was about personal information of the participant. Second section was about the sleep patterns. Third about the factors related to sleep patterns. Finally, the fourth section was about how sleeping patterns affect the academic performance; which was the grade point average (GPA). The reliability and validity of the questionnaire were checked before conducting the study. The questionnaires were distributed among the participants on 2 days.

\section{Analysis:}

After gathering and collecting the data, it was cleared, entered, coded and analyzed using SPSS program.

\section{Ethical consideration:}

Verbal consent was taken from the participants to proceed the study, and they were ensured of confidentiality. 


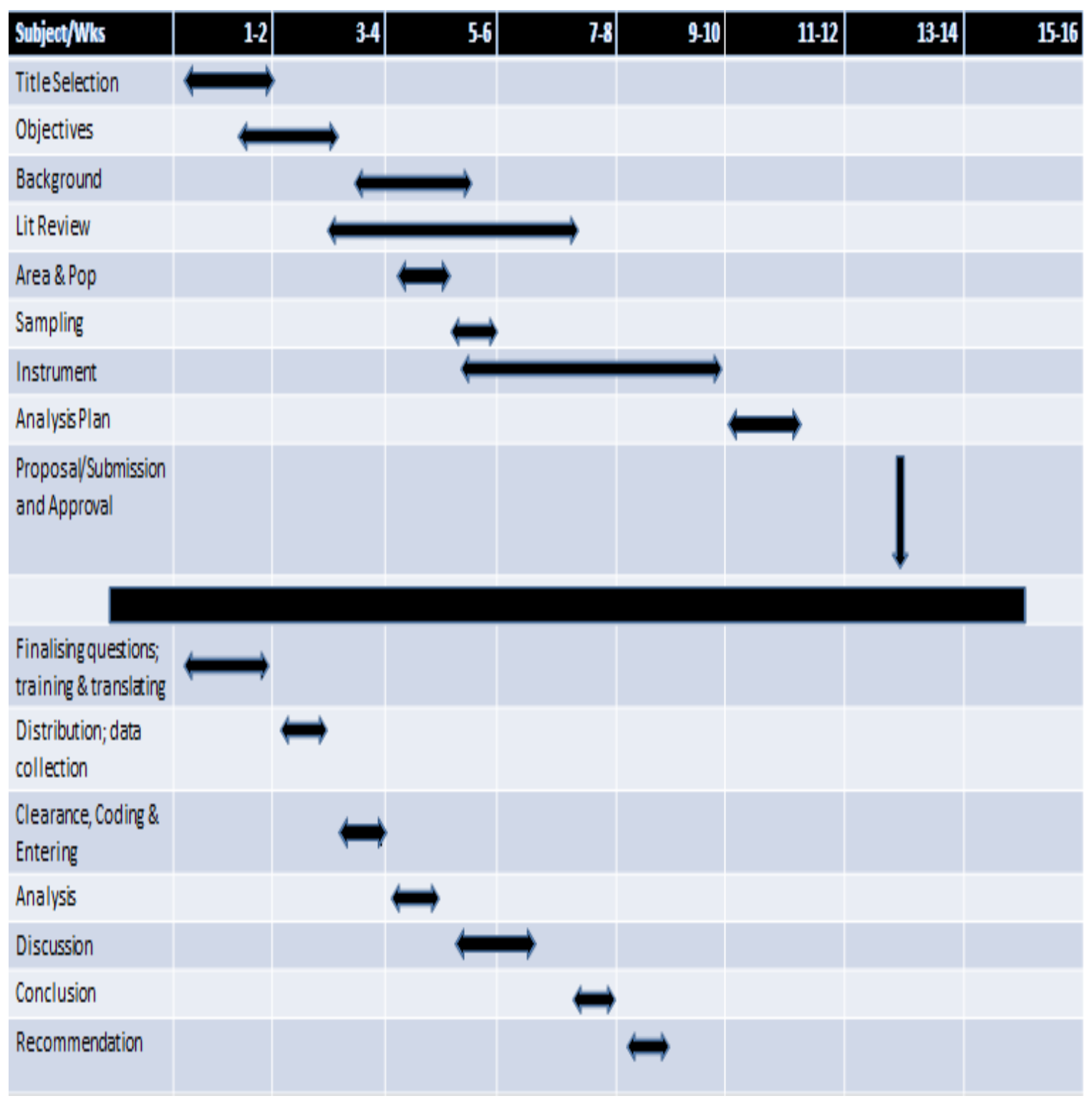

\section{Results:-}

The survey was conducted on 100 female students of AlMaarefa Colleges of Science and Technology. Out of the 100 participants $52 \%$ were medicine. $21 \%$ were pharmacology, $8 \%$ Nursing, $17 \%$ Respiratory Therapy, $2 \%$ Computer Science as shown in figure below. 


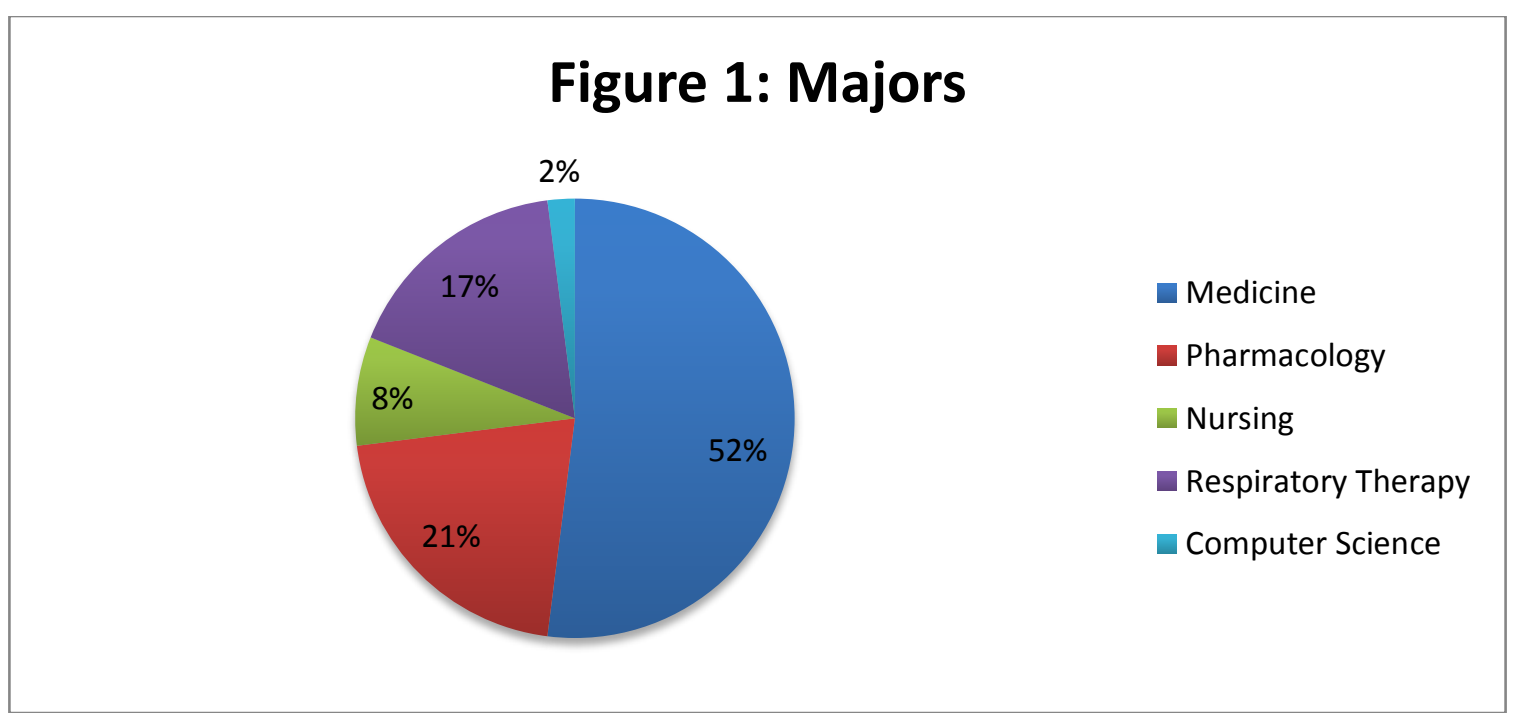

Table 1:- Sleep Pattern

\begin{tabular}{|l|l|l|l|}
\hline \multicolumn{1}{|c|}{ Type of sleep pattern } & Frequency & Percent \\
\hline \multirow{4}{*}{} & Normal & 63 & 63.0 \\
\cline { 2 - 4 } & Disturbed & 37 & 37.0 \\
\cline { 2 - 4 } & Total & 100 & 100.0 \\
\hline
\end{tabular}

Normal sleep pattern which was perceived in $63 \%$ of the students, and $37 \%$ have a disturbed sleep pattern.

Figure 2:- Hours of sleep.

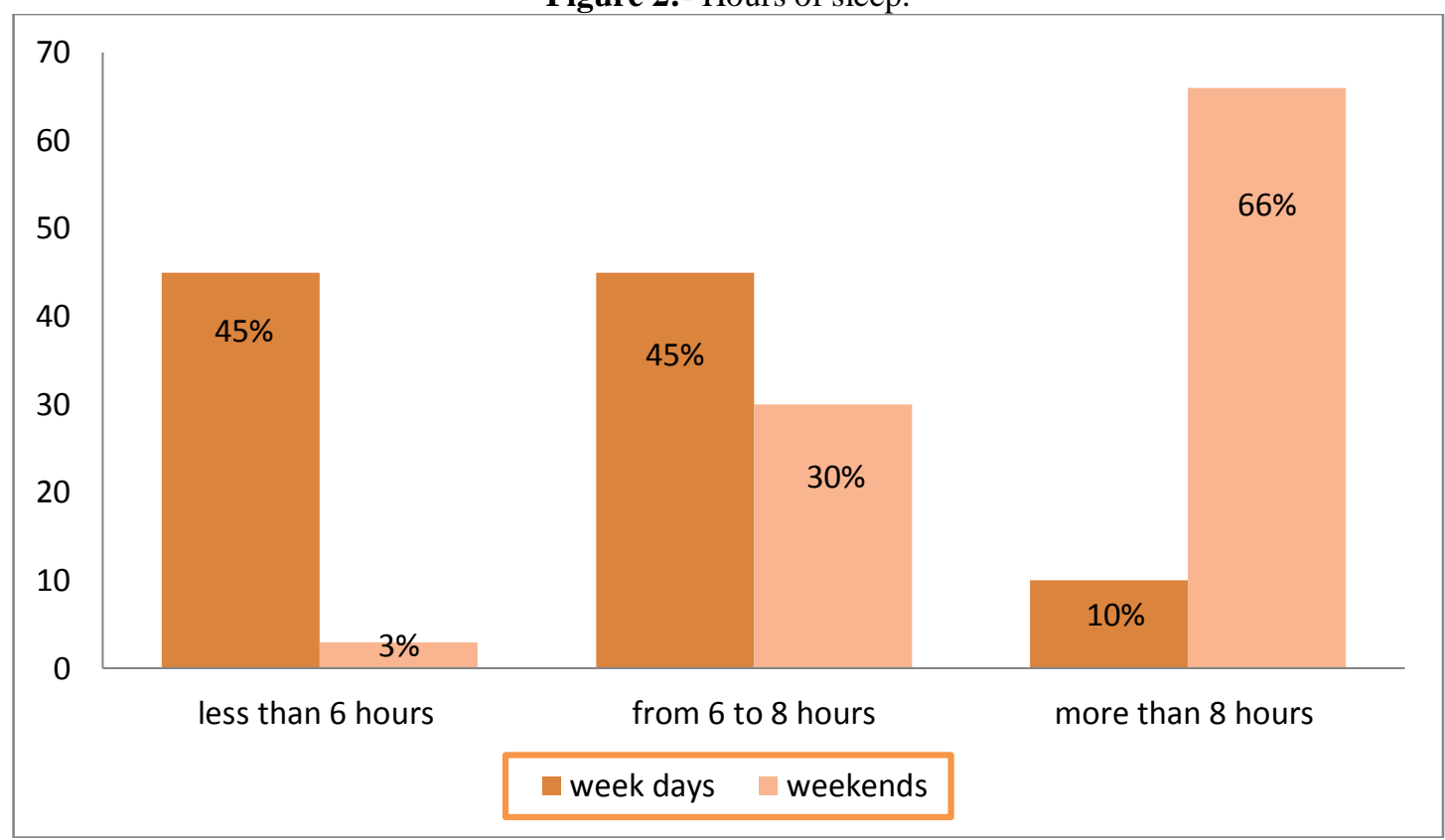

45\% of the students slept from 6 to 8 hours during weekdays and 30\% during weekends, $10 \%$ of the students slept more than 8 hours during weekdays, and $66 \%$ during weekends.

Table 2:- Factors affecting sleeping patterns

\begin{tabular}{|c|c|c|c|c|}
\hline \multirow{2}{*}{\multicolumn{2}{|c|}{ Factors effecting Sleeping patterns }} & \multicolumn{2}{|c|}{ Sleeping pattern } & \multirow[t]{2}{*}{ Tota } \\
\hline & & normal & Disturbed & \\
\hline Nightmares & Always & 6 & 21 & 27 \\
\hline
\end{tabular}




\begin{tabular}{|c|c|c|c|c|}
\hline & rarely & 56 & 16 & 72 \\
\hline & Inapplicable & 1 & 0 & 1 \\
\hline \multirow{3}{*}{$\begin{array}{l}\text { Caffeinated } \\
\text { drinks }\end{array}$} & Yes & 14 & 12 & 26 \\
\hline & No & 47 & 23 & 70 \\
\hline & Inapplicable & 2 & 2 & 4 \\
\hline \multirow{3}{*}{$\mathrm{Tv}$} & Yes & 42 & 22 & 64 \\
\hline & No & 20 & 13 & 33 \\
\hline & inapplicable & 1 & 2 & 3 \\
\hline \multirow{3}{*}{ Energy drinks } & Yes & 6 & 5 & 11 \\
\hline & No & 55 & 29 & 84 \\
\hline & inapplicable & 2 & 3 & s5 \\
\hline \multirow{2}{*}{ Naps } & Always & 47 & 16 & 63 \\
\hline & rarely & 16 & 21 & 37 \\
\hline
\end{tabular}

The table above shows the factors affecting sleeping pattern. It has been found that $78 \%$ of the students with normal sleeping rarely had nightmares. According to the value of $\mathrm{p}=0.000012$, we can say that nightmares have a relationship with developing disturbed sleeping pattern and are statistically significant. 54\% of the students with normal sleeping drank caffeine, whereas $67 \%$ of who had normal sleep pattern did not drink caffeine. $66 \%$ of the students who had normal sleep pattern watched TV before sleep, whereas $61 \%$ didn't. $65 \%$ of the students with a normal sleep pattern did not use energy drinks, whereas 56\% experienced a disturbed pattern of sleep of those who had it. 75\% of the students with a normal sleeping pattern always had naps, therefore we can say that naps are statistically significant according to the value of $\mathrm{p}=0.0017$, whereas $43 \%$ developed a disturbed pattern of sleep. Having caffeinated drinks, watching TV and having energy drinks before sleep don't show any statistical significance but show some variation.

Figure 3:- Sleep patterns in different majors

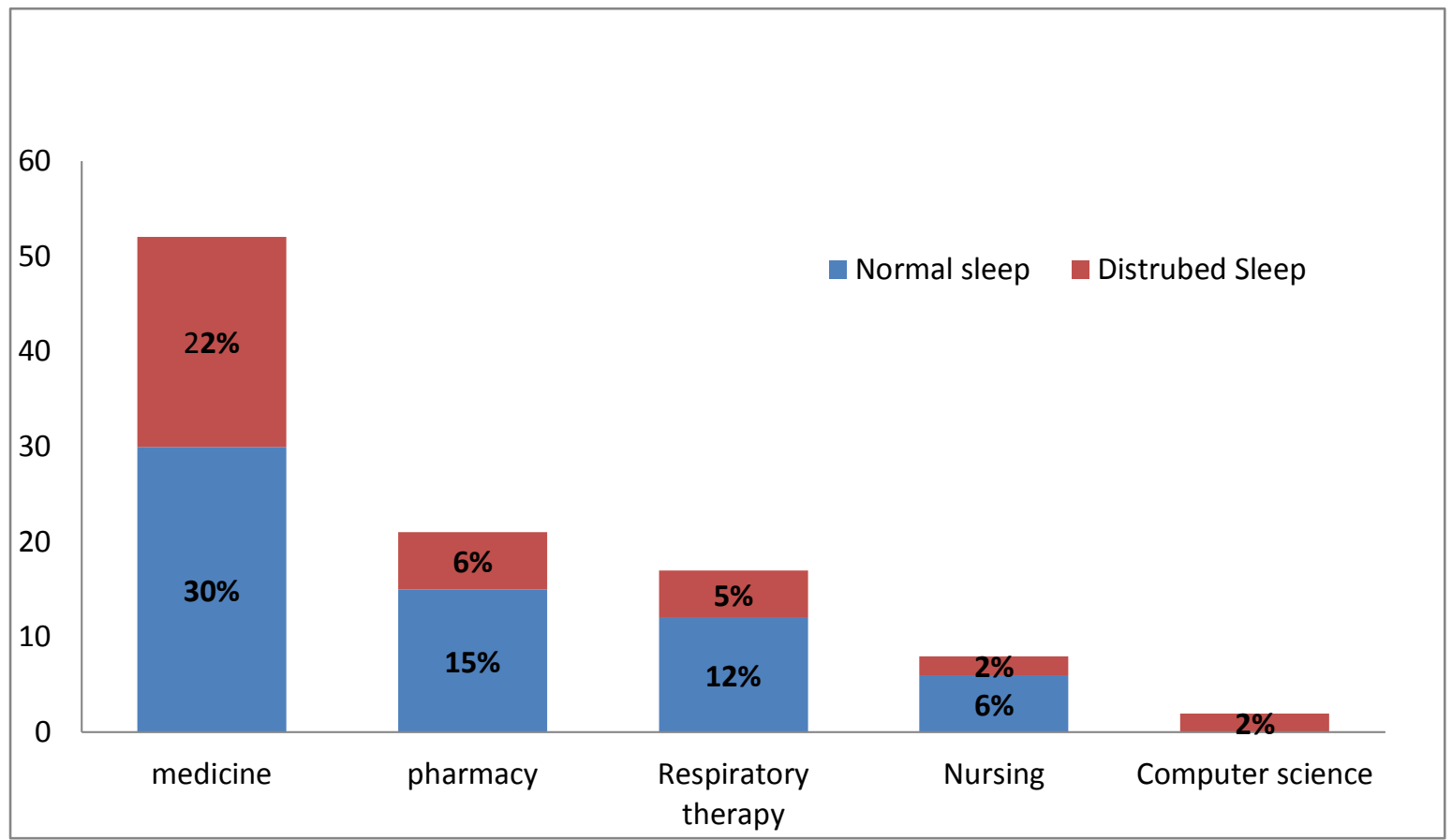

It was found that $37 \%$ of the students experienced disturbed sleep pattern out of which $22 \%$ were medical students, $6 \%$ pharmacy students, $5 \%$ Respiratory therapy students, $2 \%$ nursing students and $2 \%$ were from the department of computer science. Whereas $63 \%$ of students experience a normal pattern of sleep, out of which $30 \%$ were medical students, $15 \%$ pharmacy students, $12 \%$ Respiratory therapy students, $6 \%$ nursing students as shown in figure above. 
Table 3:- Nature of sleep pattern and Academic performance

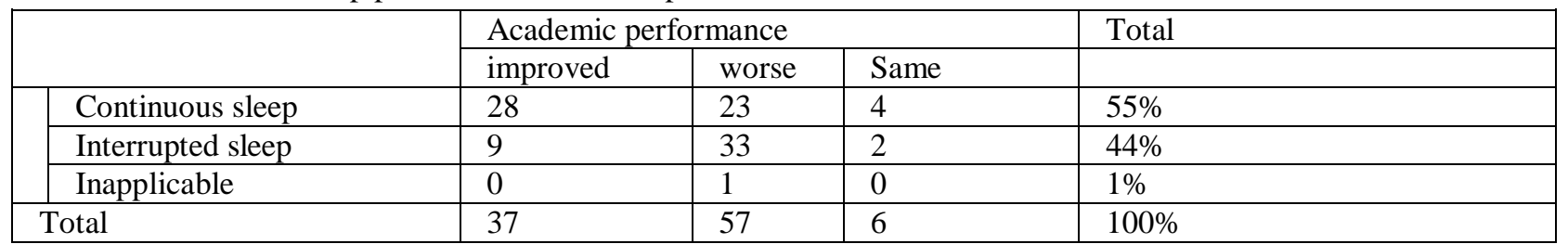

The study showed the relationship between the nature of sleep and the academic performance of the students. $51 \%$ who had a continuous sleep had their performances improved. Whereas of those who had interrupted sleep pattern, only $20 \%$ had an improved outcome. According to the value of $\mathrm{p}=0.0014$, it shows that the nature of sleep pattern has a direct association with the academic performance, and that it is statistically significant.

Figure 4: Alertness and academic performance

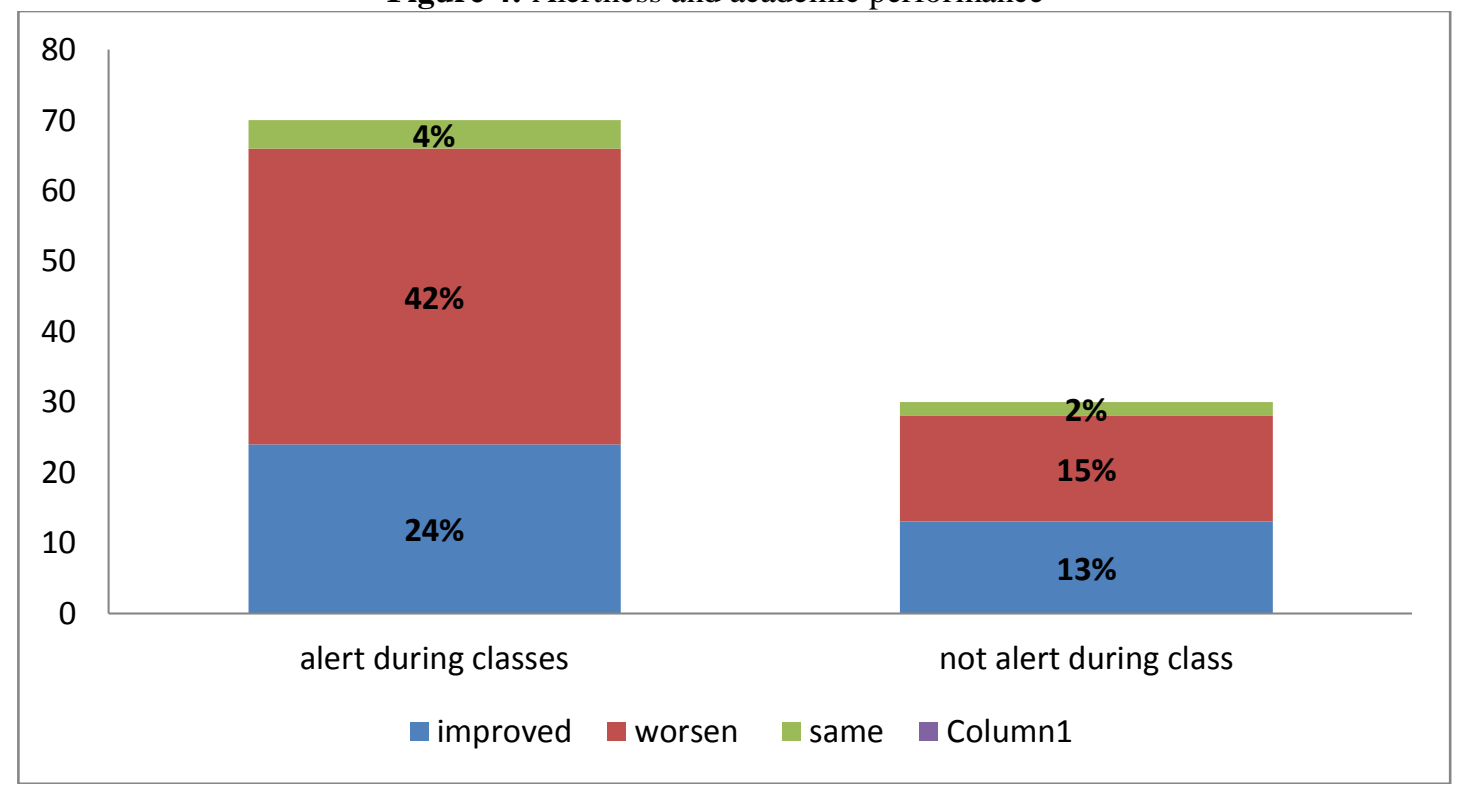

It was found that $70 \%$ were alert during classes out of which $31 \%$ had their academic performance improved. And it showed that $30 \%$ were not alert during classes, out of which $40 \%$ had an improved academic performance. However, there's no statistical significance difference.

Figure 5:- Last term GPA

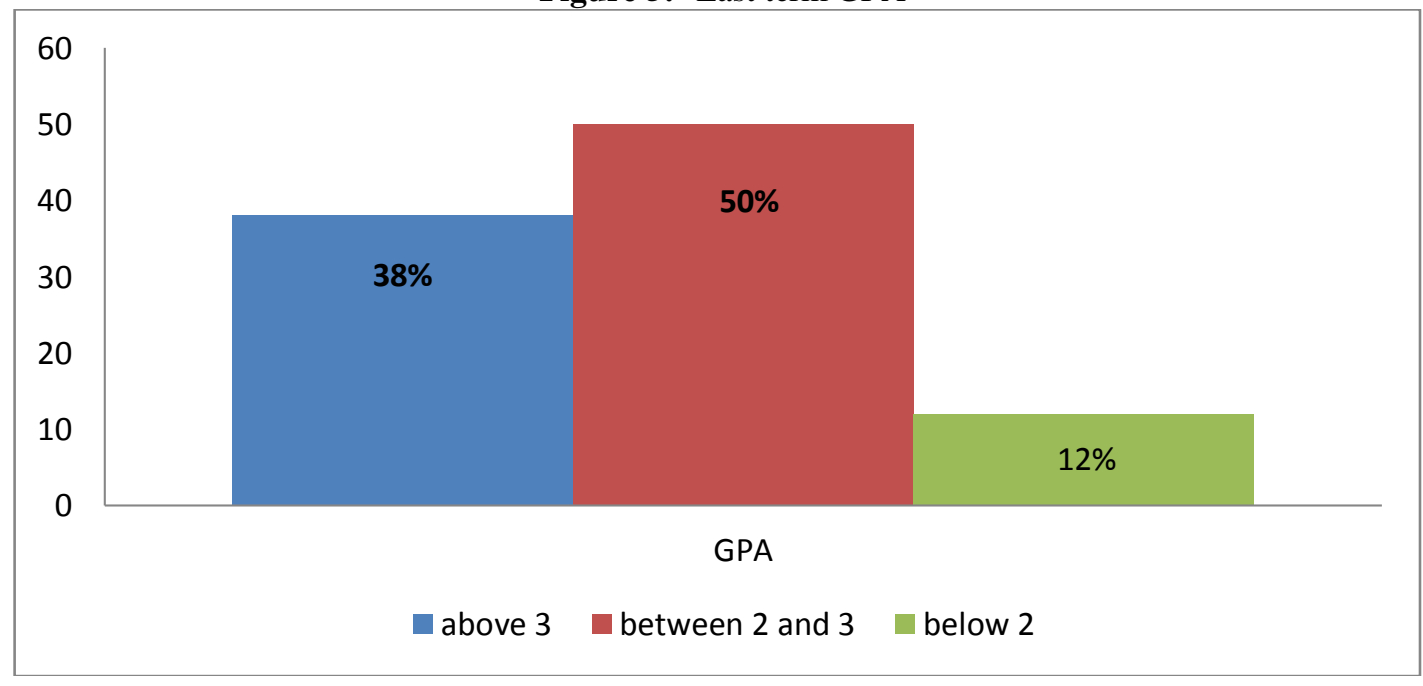


First group, student whom had GPA more than 3 which is considered as outstanding students making them about $38 \%$, second group are those whom had GPA from 2 to 3 and are considered as average students which makes about 50\%, and the last group are students with GPA below 2 and are considered as below average students.

Table 4:- Last term GPA and academic performance

\begin{tabular}{|l|l|l|l|l|l|}
\hline \multicolumn{2}{|c|}{} & \multicolumn{2}{|l|}{ academic_performance } & \multirow{2}{*}{ Total } \\
\cline { 3 - 6 } \multicolumn{2}{|c|}{} & Improved & worse & static & \\
\hline \multirow{3}{*}{ last_term_GPA } & Less than 2 & 0 & 11 & 1 & 12 \\
\cline { 2 - 6 } & From 2 to 3 & 17 & 31 & 2 & 50 \\
\cline { 2 - 5 } & More than 3 & 20 & 15 & 3 & 38 \\
\hline Total & 37 & 57 & 6 & 100 \\
\hline
\end{tabular}

The table above shows the relationship between the GPA and the academic performance of the students of the previous term. It shows excellent students (GPA of above 3) had 53\% improved academic performance. It was found that there was significant association between academic performance and GPA of the previous term, according to the value of $\mathrm{p}=0.00365$.

\section{Discussion:-}

Sleep is a vital necessity for people to conduct normal daily functions and maintain social, mental and physical health. It is also necessary for cognitive functions and memory consolidation, which are important for academic performance and career for college students.

This study has shown the presence of a relationship with minor variations between academic performance and sleep pattern among Almaarefah's college students, which initially supported the main hypothesis. In this study more of those who had an adequate, continuous time of sleep had their Grade point Average (GPA) improved since starting college. While those who had an interrupted type of sleep had their GPA decline since starting college. A recent study in The United States found that college students were at significant risk for having sleep disorders, most notably insomnia, and that those at risk for sleep disorders were performing more incompetently in school [12].

Also this study looked at the factors associated with sleep pattern holistically, such as naps, watching TV, nightmares energy and caffeinated drinks. It showed that more of those who claimed they had naps had normal sleep pattern than those who had disturbed pattern of sleep. Previous studies in USA have shown that less frequent naps have been associated with poor academic performance [12]. Watching TV before bedtime did not show any influence on their sleep patterns; and the same applies for energy and caffeinated drinks. Another study has found that exercise and caffeine consumption were not significant predictors of sleep quality [16].On the other hand, this study showed an evident relationship between nightmares and sleep pattern, for those who suffered from regular and recurrent nightmares displayed a disturbed sleep pattern more than those who had normal sleep.

It had been noticed that most of the students who claimed sleeping for 6-8 hours during weekdays have shown an improved GPA among their peers. While those who either had $>6$ or $<6$ hours, have expressed a worsened performance. Also, It has been perceived from the study that students generally sleep more hours ( $>8$ hours) in the weekends than in the weekdays, and that could be attributed to students recompensing for weekdays' sleep deprivation due to academic stress, anxiety and other psychological and habitual factors that have not been thoroughly studied in this paper. In other studies in USA, students have overwhelmingly stated that emotional and academic stress negatively impacted their sleep [16]. Also in a recent study, a decrease in the total sleeping time has been consistently shown to be correlating with lower academic performance [12]. Decreased nocturnal sleep time, late bedtimes during weekdays and weekends and increased daytime sleepiness are negatively associated with academic performance in medical students in a study done in Saudi Arabia [14].

In this study, the first GPA since entering the college was compared to the last semester's GPA to determine if the academic status of the student has improved, worsened or remained the same. Also, two sleep patterns have been perceived from the questionnaire, normal and disturbed. The rest of the results varied from those who remained the same to those who improved. This point does not support the research's hypothesis, for it does not show any consistency with the other findings nor shows any significant relation. It may also suggest factors other than sleep pattern to contribute more markedly on the academic status of the college students in Almaarefah. Previous studies 
have generally found that lower total sleeping hours, later bedtimes, longer sleep onset latency, and later rise times, less frequent naps, and inconsistent sleep schedules are all associated with worse academic performance in college or medical students [12]. Yet, in another study that was conducted on medical college students in Pakistan has showed that sleep did not display any effect on the academic performance [17].

\section{Conclusion:-}

Finally, an excellent daily performance in AlMaarefaa medical students is dependent on good quality and quantity of sleep. Sleep was positively associated with naps and continuous sleep nights, and was negatively associated with stress, anxiety and frequent nightmares. In this study, the GPA was positively associated with continuous 6-8 hours of early sleep.

\section{Recommendation:-}

1. Educate students on how to manage and organize activities and habits done before bedtime; impart how sleep and early bedtime hours are beneficial to health and academic performance.

2. Colleges should provide some ways to help students in dealing with their academic stress, such as recreation rooms and rest rooms, so the student could be more able to deal with stress.

3. Colleges should provide some counseling to help those who have sleeping problems or any kind of problems affecting their sleeping pattern.

4. Further studies should be conducted in a broader population.

\section{References:-}

1. Nordqvist C. Sleep/ Sleep Disorders/ Insomnia.National Institutes of Health.2003

2. Ali A, MajeedM, Saba K, et al. Effects of Different Sleeping Patterns on Academic Performance in Medical Students. Natural Sci.2013;11(5):1193-98

3. Sigurdsson K, Ayas N. The Public Health and Safety Consequences of Sleep Disorders. Canadian J Physiology Pharmacology.2007;8(5):179-83

4. Assad S, Costanian C, Haddad G, et al . Sleep Patterns and Disorders Among University Students in Lebanon. J Res Health Sci.2014;14(3):198-204

5. Kazim M, Abrar A. Sleep Patterns and Academic Performance in Students of Medical College in Pakistan. KUST Med J.2011;3(2):57-60

6. Stumm S., Hell B., Chamorro-Premuzic T. The Hungry Mind: Intellectual Curiosity Is the Third Pillar of Academic Performance. Perspectives on Psychological Science.2011;6(6)

7. Ninama N, Kagathara J. Sleep Wake Pattern Analysis. NHL Journal of Medical Sciences. 2012;1(1):33-36.

8. Afandi O, Hawi H, Mohammed L, et al. Sleep Quality Among University Students Evaluating the Impact of Smoking, Social Media Use, and Energy Drink Consumption on Sleep Quality and Anxiety. Student Pulse.2013; 5(6):1-3.

9. Loprinzi P, Cardinal B. Association between Objectively-Measured Physical Activity and Sleep, NHANES 2005-2006. Mental Health and Physical Activity.2011; 4 (2): 65-69.

10. Allen A, Tavares, José, Azevedo, Helena M, et al. Sleep-Wake Watterns and Academic Perfomance in University Students. Education-line. 2002; 1-4.

11. Wolfson A,Carskadon M. The Relation Between Sleep Patterns, Sleep quality, and School Performance in Medical Students. Sleep Medicine Review.2003; 7(6): 491-506.

12. Tyler D, Vatthauer K, Bramweth A, et al. The Role of Sleep in Predicting College Academic Performance: Is It a Unique Predictor. Behav Sleep Med. 2013; 11(3): 159-72.

13. Flood J, Brensinger B, Cheek S. The Impact of Sleepiness Levels on Academic Achievement for College Students. Undergraduate Research Journal for the Human Sciences. 2008; 7.

14. BaHammam A,Alaseem A,Alzakr A, et al. The Relationship Between Sleep and Wake Habits and Academic Performance in Medical Students. BMC Medical Education. 2012; 12; 61: 3-6.

15. Aabid A. Muhammad BM. Kanwal Sab, et al. Effects of Different Sleeping Patterns on Academic Performance in Medical School Students. Creative Common Attribution License. 2013; 11(5): 1193-98.

16. Lund H, Reider B, Whiting A, etal. Sleep patterns and predictors of disturbed sleep in a large population of college students. JAdolescHealth. 2010; 26(2); 124-32.

17. Kazim M, Abrar A, etal. Sleep patterns and academic performance in students of a medical college in Pakistan. KUSTMedJ. 2011; 3(2): 57-60. 


\section{Questionnaire:-}

We are Medical Students of AlMaarefa colleges. This study is made to verify the influence of sleep patterns and its related factors on the college students' academic performance as a curricular activity. Honesty is appreciated, anonymity is assured; it won't be published, and the data will be only used for the purpose of the study. We are greatly thankful for your participation.

\section{Personal information:}

Major: Medicine $\square \quad$ Pharmacy $\quad$ Nursing $\square$

Respiratory Therapy $\quad$ Computer Science $\square$

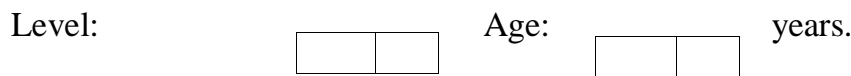

Marital Status: Single $\square \quad$ Married $\square$ Divorced $\square$ Widowed $\square$

Number of Family members: $\quad$ persons

\section{Sleep Patterns:}

A) What time do you go to bed in the week days?(Based on $24 \mathrm{hr}$ a day )

\section{O'clock}

B) What time do you go to bed in the weekends?(Based on $24 \mathrm{hr}$ a day)

O'clock

C) How long do you sleep at night during the week days? hours

D) How long do you sleep at night during the weekends? hours.

E) Do you take naps?

Always

Frequently

Rarely

Never $\square$

F) Do you have difficulties fallinga sleep?

Always $\square$

Frequently $\square$

Rarely

Never $\square$

G)How is your Sleep?

Continuousa

Interrupted $\square$

H) Do you have nightmares?

Yes $\square$

Nor

I) Do you feel sleepy in the lectures?

Always $\square$

Frequently

Rarelya

Never $\square$ 


\section{Factors related to sleep Patterns:}

A) Do you suffer from any Chronic diseases? $\square$ Yes $\square$ No

If yes, mention it:

B) Do you Take any Medications? $\square$ Yes $\square$ No

If yes, mention it:

\begin{tabular}{|c|c|c|}
\hline Questions & Yes & No \\
\hline C) Do you have a stressful life? & & \\
\hline D) Is your house environment quiet? & & \\
\hline E) Do you sleep in a comfortable room? & & \\
\hline F) Do you sleep in a separate room? & & \\
\hline G) Do you sleep with lights on? & & \\
\hline
\end{tabular}

H) What do you do before sleep?

\begin{tabular}{|l|l|l|}
\hline \multicolumn{1}{|l|}{ No } & Yes & \\
\hline 1.Excersice & & \\
\hline 2. Taking sleeping pills & & \\
\hline 3.Energy drinks & & \\
\hline 4. Caffeine & & \\
\hline 5. Watch TV & & \\
\hline 6. Take shower & \\
\hline 7. Recite Quran & \\
\hline 8.Eat heavy meals & \\
\hline 9. Others: ..................................................................... & \\
\hline
\end{tabular}

\section{Academic performance:}

A) What is your term grade point average (GPA) of the first level in college?

$\square$.

B) What is your term grade point average (GPA) of the last semester?

$\square$.

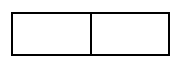

C) Do you find yourself alert and aware of your surroundings in the morning classes?

Yes $\square$

Nor

E) Doyou fully interact with your classmates and lecturer during classes?

Yes $\square$

Nor

Thank you for your participation!! 